\title{
ARTICLE
}

Interventions and public health nutrition

\section{Time trends in adherence to UK dietary recommendations and associated sociodemographic inequalities, 1986-2012: a repeated cross-sectional analysis}

\author{
Amy Yau $\mathbb{D}^{1} \cdot$ Jean Adams $\mathbb{1}^{1} \cdot$ Pablo Monsivais $\mathbb{D}^{1,2}$
}

Received: 13 June 2018 / Revised: 25 September 2018 / Accepted: 27 September 2018 / Published online: 16 November 2018

(c) The Author(s) 2018. This article is published with open access

\begin{abstract}
Background/objectives Little is known about time trends in diet quality and associated inequalities in the UK. This study aimed to examine trends in adherence to four UK dietary recommendations, overall and among sociodemographic subgroups, from 1986 to 2012.

Subjects/methods We conducted a repeated cross-sectional analysis using data from three UK diet surveys: Dietary and Nutritional Survey of British Adults 1986-87 $(n=2018)$, National Diet and Nutrition Survey (NDNS) 2000-01 $(n=1683)$ and NDNS Rolling Programme 2008-12 $(n=1632)$. We measured adherence to dietary recommendations for fruit and vegetables, salt, oily fish, and red and processed meat, estimated using food diary record data. We compared adherence across surveys and by four sociodemographic characteristics: sex, age, socioeconomic position and ethnicity.

Results Overall, population adherence to dietary recommendations was low to moderate, but improved over time. There were inequalities in adherence to all recommendations at all timepoints according to one or more sociodemographic characteristic. When inequalities were present, women, older adults, those with non-manual occupations and non-Whites were more likely to adhere to dietary recommendations. Although some dietary inequalities declined, most persisted across the three surveys.

Conclusions The persistence of most inequalities highlights the need for further interventions to reduce dietary inequalities as well as improve overall population diet. The greatest simultaneous improvement in population adherence and reduction of inequalities was observed for salt, which may reflect the success of the UK Salt Reduction Programme. Similarly comprehensive programmes should be encouraged for other dietary components.
\end{abstract}

\section{Introduction}

Dietary factors account for nearly one in five deaths and are the second leading risk factor for global disability [1]. In England, consumption of unhealthy diets is the biggest

Supplementary information The online version of this article (https:// doi.org/10.1038/s41430-018-0347-z) contains supplementary material, which is available to authorized users.

Amy Yau

ay314@cam.ac.uk

1 Centre for Diet and Activity Research, MRC Epidemiology Unit, University of Cambridge, Cambridge, United Kingdom

2 Department of Nutrition and Exercise Physiology, Elson S Floyd College of Medicine, Washington State University, Spokane, Washington, United States behavioural risk factor for morbidity and mortality, accounting for $10.8 \%$ of Disability-Adjusted Life Years lost in 2013 [2]. Current nutrition surveillance data from the United Kingdom suggest that dietary recommendations are largely not met by the population [3]. It has been estimated that if the UK population met current dietary recommendations, approximately 30,000 deaths per year could be prevented, 15,000 and 7500 of which would be a result of meeting the fruit and vegetable recommendation and salt recommendation, respectively [4]. Health benefits would also be seen by complying with recommendations for oily fish, and red and processed meat: higher fish intake, especially oily fish, is associated with lower incident rates of cardiovascular disease [5], and lower red and processed meat consumption with reduced mortality from cardiovascular disease and cancer [6].

Alongside suboptimal population diet quality, dietary risk factors are not distributed equally across population 
subgroups leading to dietary inequalities. Although inequalities in diet have been documented cross-sectionally for over 80 years [7], little is known about the evolution of dietary inequalities seen today. Studies conducted in the United States and the Netherlands found persisting or widening inequalities in diet quality by education, income, ethnicity, age and sex [8-12]. In the United Kingdom, most research has focused specifically on socioeconomic inequalities and a small number of food groups, reporting persisting gaps in fruit and vegetable intake and intake of high-fat and high-sugar foods [13-16]. Thus, little is known about other sociodemographic inequalities in the consumption of a wider range of food groups. In this study we aimed to examine trends in adherence to four dietary recommendations in the UK from 1986 to 2012, overall and among sociodemographic subgroups.

\section{Methods}

\section{Data sources}

We used data from three national diet surveys to conduct a repeated cross-sectional analysis: Dietary and Nutritional Survey of British Adults (DNSBA) 1986-87 [17], National Diet and Nutrition Survey (NDNS) 2000-01 [18] and NDNS Rolling Programme 2008-12 [19]. A rolling programme was introduced in 2008 to replace the one-off surveys previously conducted. In order to achieve a sample size comparable to previous surveys, we used data from the first four years of the Rolling Programme. All surveys used multistage random sampling and recruited a cross-section of the UK adult population. Response rates for the surveys have been reported as $70 \%, 47 \%$ and $58 \%$ for DNSBA 1986-87, NDNS 2000-01 and NDNS 2008-12, respectively. Full details on the survey methods and response rates are described elsewhere: DNSBA 1986-87 [17], NDNS 2000-01 [20] and NDNS Rolling Programme (2008-12) [3].

For DNSBA, ethics approval was obtained from the British Medical Association. For NDNS, ethics approval was obtained from the Oxfordshire A Research Ethics Committee. Written informed consent was obtained from all participants.

\section{Inclusion and exclusion criteria}

Respondents aged 19-64 years with sufficient dietary data (seven days of food diary records for DNSBA 1986-87 and NDNS 2000-01, and three or four days of food diary records for NDNS Rolling Programme 2008-12) were included. A small number of respondents were excluded due to insufficient information for assignment of socioeconomic position (SEP) $(n=29,41$ and 23 in 1986-87, 2000-01 and 2008-12, respectively).

\section{Sociodemographic characteristics}

We examined adherence to dietary recommendations by four sociodemographic characteristics: sex (men and women), age (19-40 and 41-64 years), SEP (non-manual and manual occupations) and ethnicity (Whites and nonWhites). SEP was based on the occupation of the household reference person/head of house. In DNSBA 1986-87 and NDNS 2000-01, occupational social class was classified using the Registrar General's Social Class (RGSC). The National Statistics Socioeconomic Classification (NS-SEC) replaced RGSC as the UK government's preferred measure of occupation social class in 2001 and this was used in the NDNS Rolling Programme. For comparability, we derived the household reference person's RGSC for respondents in the Rolling Programme using the Standard Occupational Classification 2000 and employment status [21]. Where this was not possible from the information available, we estimated RGSC from the NS-SEC category (for details see Supplementary Figure S1) [22]. Respondents were stratified into two categories for analysis: non-manual occupations (I Professional; II Managerial/Technical; III-NM Skilled NonManual) and manual occupations (III-M Skilled Manual; IV Partly Skilled; V Unskilled).

\section{Measuring adherence to dietary recommendations}

Dietary data were collected using food diary records, weighed 7-day diaries in the first two surveys and unweighed 4-day diaries in NDNS 2008-12. We used average person-level daily intake estimates to measure adherence to the current UK recommendations for four key dietary components related to chronic diseases: fruit and vegetables ( $\geq 400 \mathrm{~g} /$ day), oily fish ( $\geq 140 \mathrm{~g} /$ week), salt ( $\leq$ $6 \mathrm{~g} /$ day), and red and processed meat ( $\leq 80 \mathrm{~g} /$ day). The daily average intake was multiplied by seven for the oily fish recommendation, which is expressed per week.

\section{Statistical methods}

Adjusted logistic regression models were used to estimate the odds ratios (ORs), with $95 \%$ confidence intervals (CIs), for meeting the dietary recommendations by sex, age, SEP, ethnicity and timepoint, with each analysis mutually adjusted for the other variables. We examined interaction terms between the four sociodemographic characteristics and timepoint to determine whether the differences in adherence between sociodemographic subgroups changed 
over time. We used likelihood-ratio tests to compare models with and without interaction terms (sociodemographic characteristic $\times$ timepoint), in order to test the significance of each interaction. We also used an adjusted multiple logistic regression model to estimate the relative risk of achieving any number of these recommendations across the surveys. Significance levels were set at a two-tailed $P$ value $\leq 0.05$ for all tests. All statistical analyses were performed using Stata/SE 13.

\section{Sensitivity analyses}

Although all three surveys aimed to achieve population representative samples, variations in response across population subgroups can lead to non-response bias. Survey weights were provided in the second and third surveys to reduce the effects of this. In sensitivity analyses, we ran models using survey weights in the second and third surveys. This did not alter our conclusions (see Supplementary Table S1-S2). Hence, for consistency, we present all our results without survey weights.

\section{Results}

\section{Population characteristics}

Overall, 5333 individuals were included in the analyses. The proportion of respondents who were women, aged 4164 years, in non-manual households and non-White increased over time (see Table 1).

Table 1 Descriptive characteristics of study population

\begin{tabular}{lcccl}
\hline & $\begin{array}{l}1986-1987 \\
n=2018)\end{array}$ & $\begin{array}{l}2000-2001 \\
(n=1683)\end{array}$ & $\begin{array}{l}2008-2012 \\
(n=1632)\end{array}$ & $\begin{array}{l}\text { Total } \\
(n=5333)\end{array}$ \\
\hline $\begin{array}{l}\text { Sex, } n(\%) \\
\text { Men }\end{array}$ & $991(49.1)$ & $753(44.7)$ & $705(43.2)$ & $2449(45.9)$ \\
Women & $1027(50.9)$ & $930(55.3)$ & $927(56.8)$ & $2884(54.1)$ \\
Age, years, $n(\%)$ & & & \\
19-40 & $1055(52.3)$ & $794(47.2)$ & $720(44.1)$ & $2569(48.2)$ \\
41-64 & $963(47.7)$ & $889(52.8)$ & $912(55.9)$ & $2764(51.8)$ \\
Socioeconomic position ${ }^{*}, n(\%)$ & & \\
$\begin{array}{l}\text { Non-manual } \\
973(48.2)\end{array}$ & $970(57.6)$ & $987(60.5)$ & $2930(54.9)$ \\
Manual & $1045(51.8)$ & $713(42.4)$ & $645(39.5)$ & $2403(45.1)$ \\
Ethnicity, $n(\%)$ & & & \\
White & $1940(96.1)$ & $1593(94.7)$ & $1473(90.3)$ & $5006(93.9)$ \\
Non-White & $78(3.9)$ & $90(5.4)$ & $159(9.7)$ & $327(6.1)$ \\
\hline
\end{tabular}

Non-manual = professional (I), managerial/technical (II) and skilled non-manual (III-NM). Manual = skilled manual (III-M), partly skilled (IV) and unskilled (V).

*Based on RGSC classification

\section{Adherence to dietary recommendations}

Table 2 shows the proportion of respondents meeting each dietary recommendation over time and the adjusted OR for achieving each recommendation compared with the previous survey. In 2008-12, over $60 \%$ of respondents achieved the salt recommendation, under half achieved the red and processed meat recommendation, and around 20\% achieved the recommendations for fruit and vegetables or oily fish. The odds of meeting each recommendation increased over time, except for red and processed meat between 2000-01 and 2008-12, where there was no significant change. The greatest change in adherence was seen for the salt recommendation between 2000-01 and 200812: OR 2.63 (95\% CI 2.26, 3.08). Table 2 also shows the proportion of respondents meeting any number of these recommendations and the relative risk ratio for doing so between surveys. The proportion of respondents adhering to multiple dietary recommendations was low, but increased over time.

\section{Sociodemographic inequalities in meeting dietary recommendations}

Figure 1 shows the adjusted ORs (95\% CI) for meeting the four dietary recommendations by sociodemographic characteristic. We also present the results of likelihood-ratio tests used to test for interactions between the sociodemographic characteristics and timepoint, and thus changes in sociodemographic inequalities over time.

\section{Sex inequality in meeting dietary recommendations}

There was no sex inequality in achieving the fruit and vegetable recommendation at any time. However, women were more likely than men to adhere to the salt, and red and processed meat recommendations at all timepoints. The magnitude of these inequalities reduced over time $(P=0.01$ and 0.003 , respectively). Men were more likely to adhere to the oily fish recommendation than women in 1986-87, but this inequality was not observed in later surveys $(P=$ 0.001). Further details are shown in Supplementary Table S3.

\section{Age inequality in meeting dietary recommendations}

Age inequality in adherence to the fruit and vegetable recommendation was observed in all three surveys, with older adults more likely to adhere than younger adults. The magnitude of this inequality fluctuated over time: getting wider in 2000-01, then narrower in 2008-12 $(P=0.04)$. Age inequality in meeting the salt recommendation emerged 
Table 2 Changes in adherence to dietary recommendations over time

\begin{tabular}{|c|c|c|c|c|c|}
\hline & $\begin{array}{l}1986-1987 \\
(n=2018)\end{array}$ & $\begin{array}{l}2000-2001 \\
(n=1683)\end{array}$ & $\begin{array}{l}2008-2012 \\
(n=1632)\end{array}$ & $2000-01$ vs. $1986-87$ & $2008-12$ vs. $2000-01$ \\
\hline \multicolumn{4}{|c|}{ Adherence to individual dietary recommendations, $n(\%)$} & \multicolumn{2}{|c|}{ OR $(95 \% \mathrm{CI})$ of meeting recommendation } \\
\hline Fruit and vegetables & $168(8.3)$ & $271(16.1)$ & $341(20.9)$ & 1.97 (1.60 to 2.42$)$ & $1.32(1.10$ to 1.58$)$ \\
\hline Salt & $690(34.2)$ & $682(40.5)$ & $1002(61.4)$ & $1.27(1.09$ to 1.47$)$ & 2.63 (2.26 to 3.08$)$ \\
\hline Oily fish & $171(8.5)$ & $250(14.9)$ & $303(18.6)$ & $1.78(1.45$ to 2.20$)$ & $1.28(1.06$ to 1.54$)$ \\
\hline Red and processed meat & $602(29.8)$ & $739(43.9)$ & $689(42.2)$ & $1.77(1.54$ to 2.04$)$ & $0.88(0.76$ to 1.02$)$ \\
\hline \multicolumn{4}{|c|}{ Number of dietary recommendations adherent to, $n(\%)$} & \multicolumn{2}{|c|}{ RRR $(95 \% \mathrm{CI})$ of meeting recommendations } \\
\hline 0 & $892(44.2)$ & $511(30.4)$ & $318(19.5)$ & $0.69(0.59$ to 0.82$)$ & $0.62(0.51$ to 0.75$)$ \\
\hline 1 & $682(33.8)$ & $565(33.6)$ & $562(32.2)$ & REF & REF \\
\hline 2 & $388(19.2)$ & 469 (27.9) & $469(27.9)$ & $1.46(1.22$ to 1.74$)$ & $1.13(0.95$ to 1.35$)$ \\
\hline 3 & $51(2.5)$ & $113(6.7)$ & $185(11.3)$ & 2.55 (1.79 to 3.62$)$ & $1.60(1.23$ to 2.09$)$ \\
\hline 4 & $5(0.23)$ & $25(1.5)$ & $42(2.6)$ & $5.66(2.15$ to 14.91$)$ & $1.72(1.03$ to 2.88$)$ \\
\hline
\end{tabular}

$C I$ confidence interval, $O R$ odds ratio, $R R R$ relative risk ratio

ORs and RRRs are adjusted for sex, age, socioeconomic position and ethnicity between the second two surveys, favouring the older group $(P=0.01)$. The older group was more likely to meet the oily fish recommendation than the younger group. This relationship persisted without significant change across the three surveys $(P=0.44)$. There was no age inequality in adherence to the red and processed meat recommendation at any point. Further details are presented in Supplementary Table S4.

\section{Socioeconomic inequality in meeting dietary recommendations}

Socioeconomic inequality in meeting the fruit and vegetable recommendation persisted, favouring the higher socioeconomic group, but declined in magnitude over time $(P=$ $0.03)$. There was marginal socioeconomic inequality in meeting the salt recommendation in the first two surveys, which favoured the manual group. This difference did not persist to the last survey $(P=0.05)$. Socioeconomic inequality in adherence to the oily fish recommendation, favouring the higher socioeconomic group, was observed at all three timepoints without evidence of significant change $(P=0.84)$. There was marginal-to-no evidence of socioeconomic inequality in adherence to the red and processed meat recommendation at all timepoints. More information is presented in Supplementary Table S5.

\section{Ethnic inequality in meeting dietary recommendations}

Non-Whites had higher odds of meeting all dietary recommendations than Whites, except for oily fish. These inequalities persisted across all three surveys, with only ethnic inequality in adherence to the salt recommendation reducing $(P=0.02)$. More information is available in Supplementary Table S6.

\section{Discussion}

This is one of the first studies to investigate trends in dietary inequalities by multiple sociodemographic characteristics. Furthermore, this is the first study to do so by looking at adherence to multiple dietary recommendations in the United Kingdom. We found that most dietary inequalities identified in 1986-87 persisted in 2008-12. Although some inequalities reduced in magnitude over the study period, only sex inequality in meeting the oily fish recommendation was extinguished. Overall, adherence to dietary recommendations was low to moderate, but improved over time. The proportion of respondents meeting multiple recommendations also increased with time.

\section{Strengths and limitations of this study}

We used data from three national diet surveys with similar methodologies, allowing comparison over a 26-year period. Throughout, food diaries were used to collect dietary dataone of the most accurate methods of dietary assessment at the population level [23]. However, similar to all selfreported methods of dietary assessment, diaries may be subject to social desirability bias. The switch from 7-day weighed diaries to 4-day unweighed diaries in 2008-12 may have also introduced time-varying bias. We combined four years of data from the NDNS Rolling Programme in our last timepoint to achieve a sufficient sample size for subgroup analyses. Although more recent years of data from the Rolling Programme are now available, we excluded these in order to minimise any within-timepoint variations.

Across the three surveys, non-disaggregated data were used to obtain dietary intake estimates. Mixed dishes were coded by their meat/fish component. For example, $400 \mathrm{~g}$ of lamb stew, consisting of $300 \mathrm{~g}$ of lamb and $100 \mathrm{~g}$ of 


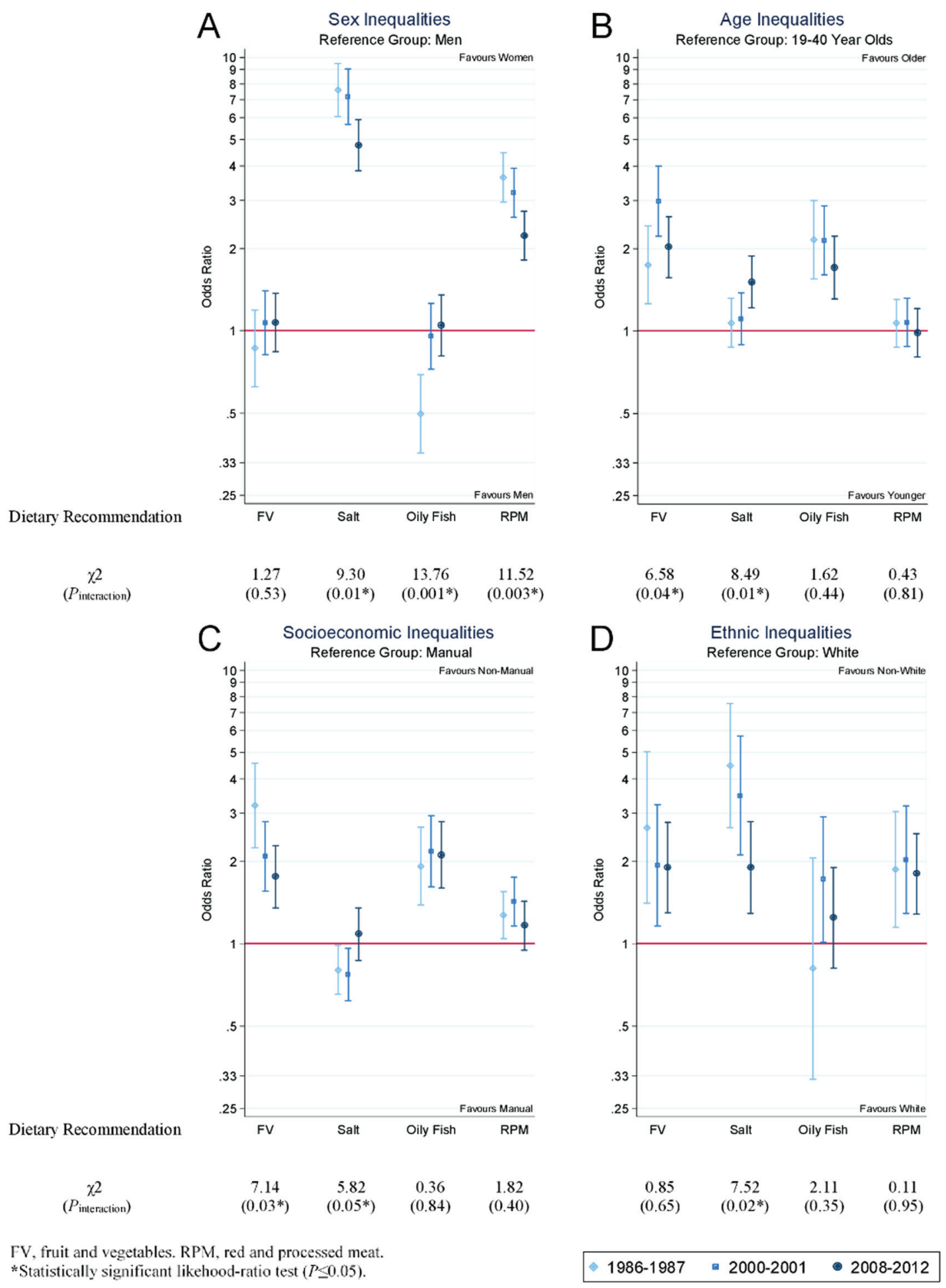

Fig. 1 Adjusted odds ratios (95\% CIs) for adhering to dietary recommendations by sociodemographic characteristics, 1986-2012. a Sex inequalities (reference group: men). b Age inequalities (reference group: 19-40 year olds). c Socioeconomic inequalities (reference

vegetables, would be coded as a lamb dish and all $400 \mathrm{~g}$ would contribute to the estimated intake of red and processed meat, but not fruit and vegetable intake. group: manual occupations). d Ethnic inequalities (reference group: White). All odds ratios (95\% CIs) are mutually adjusted for the other sociodemographic characteristics studied

Consequently, we likely overestimated oily fish, and red and processed meat intake, and underestimated fruit and vegetable intake in all surveys. More accurate estimates 
where mixed dishes are disaggregated into their ingredients were available for the NDNS Rolling Programme [24], but not for earlier surveys. To assess the implications for our study, we compared adherence to dietary recommendations using estimated intake of these food groups from disaggregated and non-disaggregated data in the NDNS Rolling Programme (see Supplementary Table S7). Overall adherence was $10 \%$ higher for fruit and vegetables, $2 \%$ lower for oily fish and $20 \%$ higher for red and processed meat, when using disaggregated estimates compared with non-disaggregated estimates. The inequalities observed were similar for the fruit and vegetable and oily fish recommendations for both methods of intake estimation. However, sex and socioeconomic inequalities in adherence to the red and processed meat recommendation were magnified when based on disaggregated estimates. An increased reliance on ready meals could mean that consumption of mixed dishes has increased over time [25], affecting the accuracy of non-disaggregated estimates more in later surveys compared to earlier surveys. We were unable to test the effect of disaggregation over time in our study, but if true, the general trend of modest improvement we observed in overall adherence is likely underestimated, whereas the reduction in sex inequality we reported for adherence to the red and processed meat recommendation may be overestimated.

In all three surveys, salt intake was consistently estimated using a nutrient databank. This was first developed for DNSBA 198-87, and subsequently updated for NDNS [26]. These estimates do not include discretionary salt added at the table or during cooking. We did not use the more accurate estimates from urinary sodium due to the small sample sizes. In NDNS 2000-01, dietary estimates of salt intake were $20 \%$ lower than urinary estimates [18], but underestimation was consistent across population subgroups [27].

We assessed adherence to four dietary recommendations, which are important to population health, prominent in public messaging and have quantifiable recommendations in the United Kingdom [28]. This provides good insight into diet quality using measurable benchmarks, but does not provide a comprehensive measure of diet quality. We excluded some dietary recommendations, such as sugar and fibre, due to limited data availability or a lack of comparability across the surveys. Other food groups of public health concern, such as sugary drinks, were excluded as there are currently no clear UK recommendations.

Survey weights were not available for DNSBA 1986-87. However, applying survey weights for NDNS 2000-01 and NDNS 2008-12 did not alter our conclusions (see Supplementary Table S1-S2). As such, it is likely that our results are generalisable to the United Kingdom as a whole. Moreover, our analyses focus on relative inequalities, which can be observed regardless of whether subgroups are population representative.

\section{Comparison of results to other studies}

Similar to our study, persistent or widening sociodemographic inequalities in diet and modest improvements in overall population diet quality were observed in the United States and the Netherlands [8-12]. Our study was mostly consistent with other UK studies, which generally found persisting, if reducing, age and socioeconomic inequalities over time [15, 29]. However, one study found socioeconomic inequality in salt intake in the NDNS Rolling Programme (2008-11), which was inconsistent with our findings [30]. This difference could be because we used averages across the four years instead of looking at trends across each year. In addition, we used RGSC to measure SEP, rather than NS-SEC.

\section{Interpretation of findings and implications for policy}

It is clear that interventions that simultaneously reduce dietary inequalities and improve overall adherence to dietary recommendations are needed. Diet quality reflects the accessibility, availability and cost of food, as well one's food preferences, nutritional knowledge and sociocultural norms $[31,32]$. These are all likely to have a role in the overall poor adherence to dietary recommendations we found. The differential effects of many of these factors across population subgroups may also be responsible for the inequalities we documented [33]. Identifying the most important determinants of both diet overall and inequalities in diet, and how to address them, is important for minimising diet-related diseases.

Cost is likely to be an important factor driving socioeconomic inequalities in diet and limiting their reduction in the United Kingdom and elsewhere. We found that socioeconomic inequalities persisted in adherence to the fruit and vegetable recommendation and oily fish recommendation. This could be due to the higher costs of diets that met these recommendations, $17 \%$ and $16 \%$, respectively, compared with diets that did not [34]. Analysis of national UK food prices found that in absolute terms, the cost of healthier foods increased to a greater extent over a 10 -year period than less healthy foods [35]. Nonetheless, food prices overall have fallen in real terms over our study period and this could have contributed to the improvement in overall adherence to dietary recommendations we observed [36]. A smaller improvement was seen between 2000-01 and 200812 , which could be associated with the rise of food prices again between 2007 and 2012 [36]. 
The persisting and emerging age inequalities we found suggest that cross-sectional age differences in diet reported elsewhere are likely true age effects rather than cohort effects. Older adults are often found to have healthier diets than younger adults. Many of the barriers to healthy eating in young adults point to the food environment, social norms and pressures, and lack of skill and motivation to prepare healthy foods $[33,37,38]$. Self-reported prevalence of some of these barriers are lower in older age groups [37, 38].

Women are thought to have healthier diets, because they tend to be more health-conscious [33]. Nonetheless, we found that sex differences in diet diminished over time. This increased equality in diet quality could be a reflection of increased gender equality in society as a whole [39]. Conversely, with more women participating in the workforce and decreasing time available for household duties over time $[40,41]$, decreasing inequalities may be a result of women's diets deteriorating rather than men's improving. Indeed, we found evidence that the proportion of women adhering to the red and processed meat recommendation decreased between 2000-01 and 2008-12. Although greater gender dietary equality should be encouraged, this should not be at the expense of women's diets. The same deterioration was seen in the non-manual group at the same time. This could also point to changes in time allocation. For example, time spent eating away from the home has increased over time, especially in the higher socioeconomic groups, and out-of-home eating is associated with lower diet quality [42, 43].

Ethnic differences in diet are often difficult to study due to the small proportion of ethnic minority individuals participating in surveys. However, we found that non-Whites had consistently higher odds of achieving dietary recommendations than Whites. This could be due to a range of factors, including different sociocultural environments and food beliefs [32]. Further focus on ethnic minorities in the United Kingdom may help to identify healthy dietary behaviours that could be promoted to the whole population.

We found reduced inequalities in adherence to the salt recommendation by sex and ethnicity over time, and a substantial increase in overall adherence between 2000-01 and 2008-12. This could be due to the UK Salt Reduction Programme introduced in 2003, which included voluntary reformulation targets for the food industry as well as public information campaigns [44, 45]. Previous studies suggest that the combination of behavioural and structural elements of this programme led to its success in reducing inequalities [46]. In contrast, a lack of such coordinated effort for other components of diet may explain persisting inequalities. An evaluation of the UK's 5-a-day public information campaign, which aims to increase fruit and vegetable consumption, found small improvements in overall intake and inequality reduction two years following its introduction [47]. This suggests that public awareness alone is not enough to improve population diet quality substantially. The comprehensive multi-component programmes for sugar and calorie reduction recently announced in England should, therefore, be welcomed from an equity point of view $[48,49]$.

\section{Conclusions}

We found that most sociodemographic inequalities in adherence to key UK dietary recommendations persisted between 1986 and 2012. Alongside, we found low-tomoderate, but improving, overall adherence to dietary recommendations. Further interventions to reduce dietary inequalities in the United Kingdom as well as improve overall population diet quality are needed.

Acknowledgements This work was undertaken by the Centre for Diet and Activity Research (CEDAR), a UKCRC Public Health Research Centre of Excellence. Funding from Cancer Research UK, the British Heart Foundation, the Economic and Social Research Council, the Medical Research Council, the National Institute for Health Research and the Wellcome Trust, under the auspices of the UK Clinical Research Collaboration, is gratefully acknowledged. PM also received support from the Health Equity Research Center at Washington State University. The funders had no role in the study design, data collection, analysis, interpretation, or writing, nor in the decision to submit the article for publication.

Author contributions AY and PM conceived the idea for the study and formulated the research question. The study analysis was designed by AY, PM and JA. AY led on the data analysis, supported by JA and PM. All authors contributed to the interpretation of the data. AY drafted the initial manuscript. All authors contributed to the content and critical revision of the report, and agreed to submit the report for publication.

\section{Compliance with ethical standards}

Conflict of interest The authors declare that they have no conflict of interest.

Open Access This article is licensed under a Creative Commons Attribution 4.0 International License, which permits use, sharing, adaptation, distribution and reproduction in any medium or format, as long as you give appropriate credit to the original author(s) and the source, provide a link to the Creative Commons license, and indicate if changes were made. The images or other third party material in this article are included in the article's Creative Commons license, unless indicated otherwise in a credit line to the material. If material is not included in the article's Creative Commons license and your intended use is not permitted by statutory regulation or exceeds the permitted use, you will need to obtain permission directly from the copyright holder. To view a copy of this license, visit http://creativecommons. org/licenses/by/4.0/.

\section{References}

1. GBD 2016 Risk Factors Collaborators Global, regional, and national comparative risk assessment of 84 behavioural, environmental and occupational, and metabolic risks or clusters of 
risks, 1990-2016: a systematic analysis for the Global Burden of Disease Study 2016. Lancet. 2015;2017:1345-422.

2. Newton JN, Briggs ADM, Murray CJL, Dicker D, Foreman KJ, Wang $\mathrm{H}$, et al. Changes in health in England, with analysis by English regions and areas of deprivation, 1990-2013: a systematic analysis for the Global Burden of Disease Study 2013. Lancet. 2015;386:2257-74.

3. Public Health England. National Diet and Nutrition Survey Results from Years 1, 2, 3 and 4 (combined) of the Rolling Programme (2008/2009-211-2012). London: Public Health England; 2014.

4. Scarborough P, Nnoaham KE, Clarke D, Capewell S, Rayner M. Modelling the impact of a healthy diet on cardiovascular disease and cancer mortality. J Epidemiol Community Heal. 2012;66:420-426.

5. Mori TA. Marine OMEGA-3 fatty acids in the prevention of cardiovascular disease. Fitoterapia. 2017;123:51-58.

6. Wang X, Lin X, Ouyang YY, Liu J, Zhao G, Pan A, et al. Red and processed meat consumption and mortality: dose-response metaanalysis of prospective cohort studies. Public Health Nutr. 2015;19:893-905.

7. Boyd Orr J. Food, Health, and Income. London: Macmillan and Co; 1936.

8. Popkin BM, Zizza C, Siega-Riz AM. Who is leading the change? U.S. dietary quality comparison between 1965 and 1996. Am J Prev Med. 2003;25:1-8.

9. Hulshof K, Brussaard J, Kruizinga A, Telman J, Löwik M. Socioeconomic status, dietary intake and $10 \mathrm{y}$ trends: the Dutch National Food Consumption Survey. Eur J Clin Nutr. 2003;57:128-37.

10. Wang DD, Leung CW, Li Y, Ding EL, Chiuve SE, Hu FB. et al. Trends in dietary quality among adults in the United States, 1999 through 2010. JAMA Intern Med. 2014;174:1587-95.

11. Groth M, Sorensen M, Matthiessen J, Fagt S, Landvad N. Disparities in dietary habits and physical activity in Denmark and trends from 1995 to 2008. Scand J Public Health. 2014;42:611-20.

12. Rehm CD, Peñalvo JL, Afshin A, Mozaffarian D, CJ M, G D, et al. Dietary intake among US adults, 1999-2012. JAMA. 2016;315:2542-53.

13. Inchley J, Todd J, Bryce C, Currie C. Dietary trends among Scottish schoolchildren in the 1990s. J Hum Nutr Diet. 2001;14:207-16.

14. Johnson B, Hackett A. Trends in fruit, vegetable and salad intakes in 9-10-year-old schoolchildren living in Liverpool, 2000-25. Public Health Nutr. 2007;10:252-5.

15. Rogers S, Pryer JA, Tobias M, Jackson G, Yeh L-C, Huang K. et al. Who consumed 5 or more portions of fruit and vegetables per day in 1986-1987 and in 2000-2001?. Public Health Nutr. 2012;15:1240-7.

16. Barton KL, Wrieden WL, Sherriff A, Armstrong J, Anderson AS. Trends in socio-economic inequalities in the Scottish diet: 20012009. Public Health Nutr. 2015;18:2970-80.

17. Office of Population Censuses and Surveys, Social Survey Division. Dietary and Nutritional Survey of British Adults, 1986-1987 [computer file]. https://doi.org/10.5255/UKDA-SN-2836-1.

18. Office for National Statistics, Social and Vital Statistics Division, Food Standards Agency. National Diet and Nutrition Survey: Adults Aged 19 to 64 Years, 2000-2001 [computer file]. https:// doi.org/10.5255/UKDA-SN-5140-1.

19. NatCen Social Research, MRC Elsie Widdowson Laboratory, University College London Medical School. National Diet and Nutrition Survey Years 1-4, 2008/09-2011/12 [computer file]. 8th edn. https://doi.org/10.5255/UKDA-SN-6533-7.

20. Henderson L, Gregory J, Swan G. The National Diet \& Nutrition Survey: Adults Aged 19 to 64 Years. Volume 1: Types and Quantities of Food Consumed. Her Majesty's Stationery Office: Norwich; 2002.
21. Rose D, Pevalin D. Derivations of Social Class. 2001. https://www.iser.essex.ac.uk/archives/nssec/derivations-of-socialclass. Accessed 17 Oct 2017.

22. Rose D, Pevalin D, O'Reilly K. The National Statistics Socioeconomic Classification: Origins, Development and Use. Her Majesty's Stationery Office: Essex; 2005.

23. Day N, McKeown N, Wong M, Welch A, Bingham S. Epidemiological assessment of diet: a comparison of a 7-day diary with a food frequency questionnaire using urinary markers of nitrogen, potassium and sodium. Int J Epidemiol. 2001;30:309-17.

24. Fitt E, Mak T, Stephen A, Prynne C, Roberts C, Swan G, et al. Disaggregating composite food codes in the UK National Diet and Nutrition Survey food composition databank. Eur J Clin Nutr. 2010;64:32-36.

25. Olsen NV, Sijtsema SJ, Hall G. Predicting consumers' intention to consume ready-to-eat meals. role Moral Attitude Appetite. 2010;55:534-9.

26. Lennox A, Fitt E, Whitton C, Roberts C, Prynne C, Stickley E et al. Results from Years 1-4 (combined) of the Rolling Programme. 2008 https://www.food.gov.uk/sites/default/files/media/ document/ndns-appendix-a.pdf. Accessed 7 Sept 2018.

27. Ji C, Kandala N-B, Cappuccio FP. Spatial variation of salt intake in Britain and association with socioeconomic status. BMJ Open. 2013;3:e002246.

28. Scientific Advisory Committee on Nutrition. The nutritional wellbeing of the British population. TSO: London; 2008.

29. Wrieden WL, Connaghan J, Morrison C, Tunstall-Pedoe H, Williams C, Hunt C, et al. Secular and socio-economic trends in compliance with dietary targets in the north Glasgow MONICA population surveys 1986-1995: did social gradients widen? Public Health Nutr. 2004;7:835-42.

30. Ji C, Cappuccio FP. Socioeconomic inequality in salt intake in Britain 10 years after a national salt reduction programme. BMJ Open. 2014;4:e005683.

31. Miller V, Yusuf S, Chow CK, Dehghan M, Corsi DJ, Lock K, et al. Availability, affordability, and consumption of fruits and vegetables in 18 countries across income levels: findings from the Prospective Urban Rural Epidemiology (PURE) study. Lancet Glob Heal. 2016;4:e695-e703.

32. Osei-Kwasi HA, Nicolaou M, Powell K, Terragni L, Maes L, Stronks K, et al. Systematic mapping review of the factors influencing dietary behaviour in ethnic minority groups living in Europe: a DEDIPAC study. Int $J$ Behav Nutr Phys Act. 2016;13:85.

33. Munt AE, Partridge SR, Allman-Farinelli M. The barriers and enablers of healthy eating among young adults: a missing piece of the obesity puzzle: A scoping review. Obes Rev. 2017; 18:1-17.

34. Jones NRV, Tong TYN, Monsivais P. Meeting UK dietary recommendations is associated with higher estimated consumer food costs: an analysis using the National Diet and Nutrition Survey and consumer expenditure data, 2008-12. Public Health Nutr. 2017;21:948-56.

35. Jones NRV, Conklin AI, Suhrcke M, Monsivais P. The growing price gap between more and less healthy foods: analysis of a novel longitudinal UK dataset. PLoS ONE. 2014;9:e109343.

36. Department for Environment Food and Rural Affairs. Food statistics pocketbook 2012 (in year update). York: Department for Environment Food and Rural Affairs; 2013.

37. de Mestral C, Stringhini S, Marques-Vidal P. Barriers to healthy eating in Switzerland: a nationwide study. Clin Nutr. 2016;35:1490-8.

38. de Mestral C, Khalatbari-Soltani S, Stringhini S, MarquesVidal P. Fifteen-year trends in the prevalence of barriers to healthy eating in a high-income country. Am J Clin Nutr. 2017;105:660-8. 
39. British Council. Gender equality and empowerment of women and girls in the UK. Manchester: British Council; 2016.

40. Gimenez-Nadal JI, Sevilla A. Trends in time allocation: a crosscountry analysis. Eur Econ Rev. 2012;56:1338-59.

41. Office for National Statistics. Women in the labour market. London: Office for National Statistics; 2013.

42. Cheng S, Oslen W, Southerton D, Warde A. The changing practice of eating: evidence from UK time diaries, 1975 and 2000. Br J Sociol. 2007;58:39-61.

43. Lachat C, Nago E, Verstraeten R, Roberfroid D, Van Camp J, Kolsteren P. Eating out of home and its association with dietary intake: a systematic review of the evidence. Obes Rev. 2012;13:329-46.

44. Wyness LA, Butriss JL, Stanner SA. Reducing the population's sodium intake: the UK Food Standards Agency's salt reduction programme. Public Health Nutr. 2011;15:254-61.
45. He F, Brinsden H, Macgregor G. Salt reduction in the United Kingdom: a successful experiment in public health. J Hum Hypertens. 2014;28:345-52.

46. Hyseni L, Elliot-Green A, Lloyd-Williams F, Kypridemos C, O'Flaherty M, McGill R, et al. Systematic review of dietary salt reduction policies: Evidence for an effectiveness hierarchy? PLoS ONE. 2017;12:e0177535.

47. Capacci S, Mazzocchi M. Five-a-day, a price to pay: an evaluation of the UK program impact accounting for market forces. J Health Econ. 2010;30:87-98.

48. Tedstone A, Targett V, Owtram G, Pyne V, Allen R, Bathrellou K, et al. Sugar reduction: achieving the $20 \%$. A technical report outlining progress to date, guidelines for industry, 2015 baselines levels in key foods and next steps. London: Public Health England; 2017.

49. Tedstone A, Targett V, Mackinlay B. Calorie reduction: the scope and ambition for action. London, 2018. 